\title{
Izbor tipa i optimizacija snage solarnog sistema za snabdevanje električnom energijom pumpnog postrojenja
}

$\mathrm{D}$ ostupnost energije Sunca, bez obzira na njen prekidni karakter, i primena politike održivog razvoja uslovili su finansiranje istraživanja, subvencionisanje proizvodnje i primenu podsticajnih mera za korišćenje solarnih fotonaponskih sistema. Dosadašnji deo XXI veka obeležila je njihova masovna proizvodnja i primena. Ovo je globalni proces, koji je rezultirao da npr. u 2018. godini u Nemačkoj ukupan vršni instalirani kapacitet fotonaponskih sistema bude $46 \mathrm{GW}$ [1]. Prepuštajući se ovom procesu i Republika Srbija je u primeni, na žalost ne i u razvoju i proizvodnji, značajno povećala instalirani kapacitet fotonaponskih elektrana. On trenutnno iznosi $8815.7 \mathrm{~kW}$, od čega 5340 $\mathrm{kW}$ pripada sistemima na zemlji [2]. O dinamici u ovoj oblasti najbolje svedoče podaci da je za fotonaponsku elektranu nazivne snage $200 \mathrm{~kW}$, sniženje investicionih troškova $66 \%$ i troškova rada i održavanja $47 \%$ u periodu od 2010. do 2018. godine [3].

\section{Uvod}

Rad koji se izlaže je posledica aktivnosti na izgradnji fotonaponske elektrane srednje snage na zemlji i cilj mu je da pokaže da li je, u kom slučaju i u kakvoj konfiguraciji ekonomična primena ovih sistema za snabdevanje električnom energijom pumpnog postrojenja koje se koristi u sistemu vodosnabdevanja. Dakle, rad se ne bavi tehničkim razvojem niti daje pregled razvoja tehnologije, već se bavi tehnoekonomskim aspektima primene ovih sistema $\mathrm{u}$ sadašnjem vremenu u Republici Srbiji. Cilj mu je da pokaže koji su sistemi (konfiguracije) ekonomični za primenu. Uzimajući u obzir veličinu pumpnog postrojenja u kom se primenjuje, rad je limitiran na fotonaponske sisteme srednje snage, između 100 i $1000 \mathrm{~kW}$ [3].

\subsection{Karakteristike lokacije, pumpnog postrojenja i vrste analiziranih sistema}

Pumpno postrojenje je potrošač na srednjem naponu, odobrene snage $153 \mathrm{~kW}$, sa maksimalnom nazivnom snagom od $260 \mathrm{~kW}$ i nalazi se neposredno uz bunare koji se koriste za vodosnabdevanje grada Kraljeva. Uz zgradu pumpnog postrojenja je tzv. sanitarna zona sa placom, livadom površine 6 ha. Centralni deo placa na kom bi se smestila elektrana ima geografsku širina $43.719^{\circ}$ i dužinu $20.637^{\circ}$. Plac je relativno ravan, bez prepreka i gotovo bez nadvišenja na horizontu koja mogu da skraćuju periode osunčanja.

Slika 1. prikazuje prosečnu promenu relativne snage pumpanja u toku jednog dana. Ona ne zavisi od doba godine. Električna snaga pumpanja se menja u relativno uskim granicama od $87 \%$ do $110 \% \mathrm{u}$ odnosu na prosečnu dnevnu snaga od $100 \%$. Ovo je bilo neočekivano kao što je i činjenica da prosečna dnevna snaga varira u opsegu od $120 \mathrm{~kW}$ u septembru do $146 \mathrm{~kW}$ u februaru. Ova varijacija pre svega zavisi od klime i karakteristika potrošača koji se snabdevaju sa datog postrojenja.

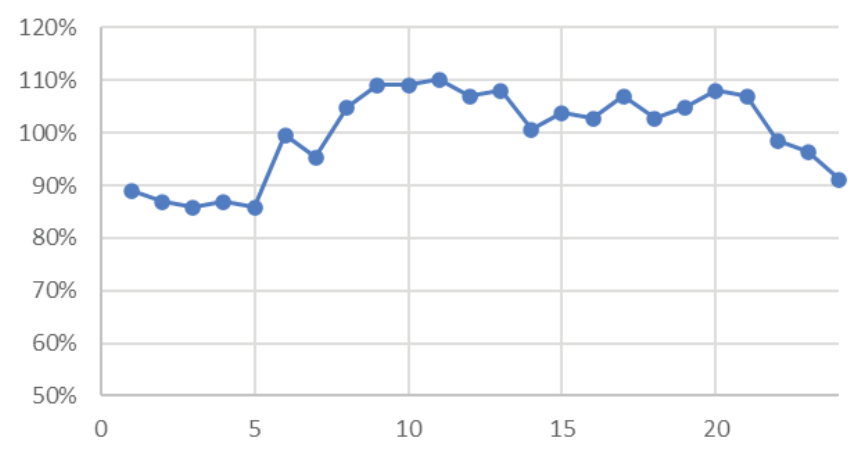

Slika 1: Prosečna promena relativne snage pumpanja u toku dana. $100 \%$ je prosečna dnevna snaga pumpanja koja zavisi od doba godine

U radu se za snabdevanje pumpnog postrojenja analiziraju elektrane nominalne električne snage u opsegu od $100 \mathrm{~kW}$ do 400 kW u sledećim konfiguracijama: (1) sa fiksno (statički) postavljenim solarnim panelima, (2) sa panelima za jednoosno praćenje i (3) dvoosno praćenje Sunca, (4) sistemi koji električnu energiju predaju samo za pumpanje vode, (5) sistemi koji električnu energiju predaju za pumpanje vode a višak plasiraju u distributivnu mrežu, i (6) sistemi koji potreban deo električnu energiju predaju direktno za pumpanje a višak akumuliraju i u periodima kad nema sunčevog zračenja predaju sistemu za pumpanje vode. U svim navedenim konfiguracijama, analize su vršene za različite cene električne energije u 2020. godini: sa subvencionisanim tarifama, sa postojećom cenama pri različitim faktorima snage i sa prodajom električne energije distributivnoj mreži po tržišnoj ceni.

\section{$2 \quad$ Metodologija}

Tehnoekonomska analiza se sastojala iz sledećih sukcesivnih koraka:

1. Meteorološki podaci: dozračena Sunčeva energija, karakteristike vetra, temperatura, vazdušni pritisak i tipična 
meteorološka godina uzete su sa PVGIS-a [4], sistemskog alata sa bazama podataka. Korišćene su preporučene baze podataka: PVGIS-SARAH i PVGIS-COSMO za datu lokaciju i proverene pomoću podataka sa najbliže hidrometeorološke stanice [5].

2. Performanse fotonaponskih sistema sa stacionarnim i kolektorima sa jednoosnim i dvoosnim praćenjem Sunca, čije su nominalne snage manje ili jednake potrošnji električne energije pumpnog postrojenja određivane su pomoću alata PVGIS [5].

3. U slučajevima kad je nominalna snaga elektrane veće od prosečne snage pumpnog postrojenja javlja se višak energije, koji se ili skladišti u baterijama kod hibridnih postrojenja ili se predaje elektrodistributivnom sistemu. Višak energije je računat kao razlika trenutne snage fotonaponske elektrane i potrošnje pumpnog sistema (videti Sliku 1.) i integraljen. Trenutna snaga je računata pomoću podataka za tipičnu meteorološku godinu [4] pomnoženih sa stepenima korisnosti sistema, koji zavisi od doba dana i intenziteta zračenja i koji je za stacionarne i kolektore sa jedno i dvoosnim praćenjem Sunca uzet iz reference [6].

4. Analizirani sistemi su ocenjivani na osnovu dinamičke analize prihoda i rashoda sa uzimanjem u obzir promene vrednosti novca u vremenu tzv. „Cost Benefit” analiza [7]. Analiza je rađena uz pretpostavku da je projekat finansiran kreditnim sredstvima sa kamatnom stopom od $2.5 \%$ godišnje bez tzv. ,grejs“ perioda.

\subsection{Fotonaponskipaneli}

Tokom poslednje decenije fotonaponskim panelima je drastično opala cena dok im je efikasnost blago porasla [3,6]. Najčešće se izrađuju od [6]:

- monokristalnog silicijum,

- višekristalnog silicijuma,

- $\quad$ tankog filma kadmijuma i telura CdTe

- $\quad$ sa napredni silicijumskim dizajnom, i

- $\quad$ sa koncentratorima solarne energije.

U 2018. godini u SAD-u tipična efikasnost panela iznosila je $19.1 \%$ [3]. Danas, dve godine kasnije ta je efikasnost malo porasla i na tržištu mogu da se nabave paneli koji imaju stepen korisnosti pri standardnim uslovima testiranja i malo preko $20 \%$. Sa vremenom stepen korisnosti panela opada ali na osnovu zahteva standarda ne sme da opadne više od $20 \%$ u odnosu na deklarisani stepen korisnosti za 20 godina. Prosečno godišnje opadanje stepena korisnosti panela iznosi $0.7 \%$ /godišnje, s tim da većina ispitivanih panela ima opadanje $0.5 \%$ godišnje [8]. Najčešće snage Pcol fotonaponskih kolektora na tržištu su između 320 i $420 \mathrm{~W}$, pri čemu im je linearizovana cena Ccol u €:

$$
C_{c o l}=0,1225 P_{c o l}+34,108
$$

\subsection{Inverteri}

Inverteri služe da jednosmernu pretvore u naizmeničnu struju. Generalno postoje dve vrste invertera: za direktno priključenje na distributivnu mrežu i hibridni inverteri koji istovremeno mogu da povezuju: akumulatore, potrošače i distributivnu mrežu.

Slika 2. prikazuje lineranu krivu koja daje odnos između cene inverera Cinv $(€)$ i nominalne snage elektrane PPV $(\mathrm{kW})$. Na isti način određena je i cena hibridnih invertera Chyb inv $(€) \mathrm{u}$ zavisnosti od snage elektrane PPV (kW) i ona iznosi:

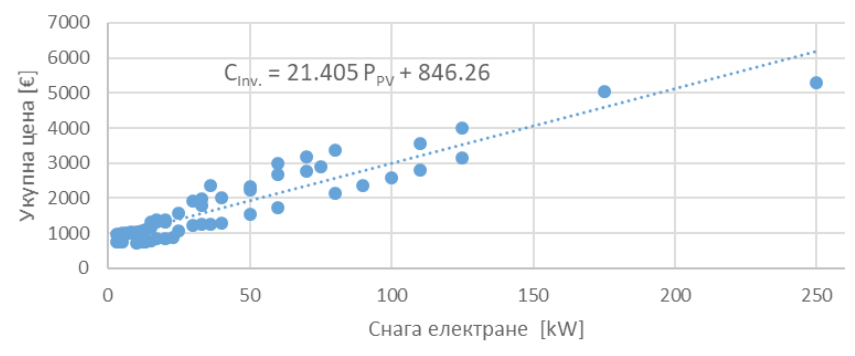

Slika 2: Cene invertera (pretvarača) za direktno priključenje na distributivnu mrežu u zavisnosti od snage elektrane. Tačke na dijagramu prikazuju zvanično dobijene ponude. Sve cene koje se prikazuju u radu dobijene su na osnovu zvaničnih ponuda. Zbog velikog broja ponuda one su namerno izostavljene iz liste referenci.

$$
C_{\text {hyb inv }}=171,73 P_{p v}-322,82
$$

\subsection{Dodatne mehaničke i električne komponente}

Dodatne mehaničke komponente služe za postavljanje, učvršćivanje i nošenje panela. Cena im ne zavisi od nominalne električne snage elektrane. U SAD-u iznosi 0.08 \$ W [3], dok je u Švajcarskoj u 2015. godine iznosila 15\% od ukupne cene investicije [6]. U radu je cena mehaničkih komponenti pretpostavljeno da iznosi $6.54 \mathrm{~s} € / \mathrm{W}$ na osnovu tržišnih cena u našoj zemlji.

U dodatne električne komponente spadaju provodnici, prekidači, udruživači, ormarići, bužiri, uzemljenje, sistem nadgledanja, merni uređaji, osigurači i prekidači, i ostala električna oprema za podršku fotonaponskoj elektrani. Ovi troškovi su računati na osnovu podataka prikazanih na Slici 3. Naime, odnos cena električnih komponenti i cene fotonaponskih modula je zadržan kao na pomenutoj slici samo je cena modula uzeta iz poglavlja 2.1 .

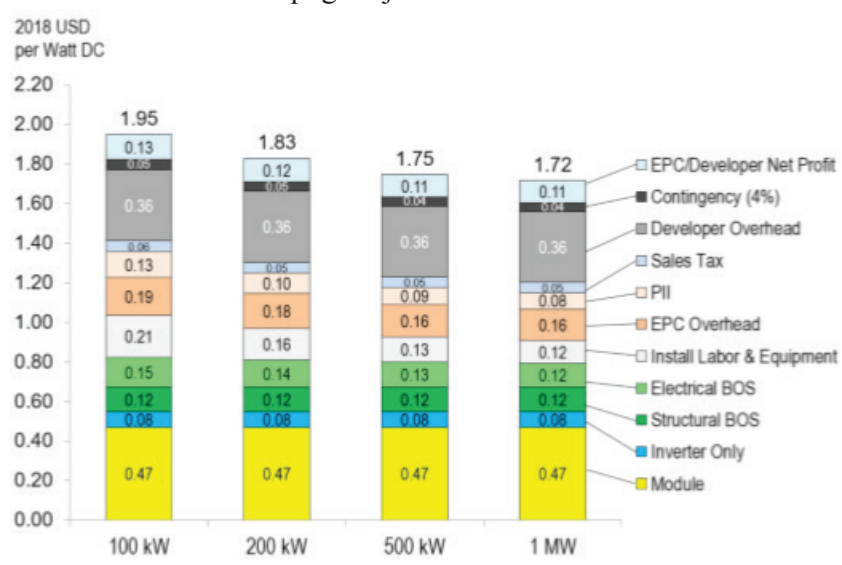

Slika 3: Međupovezanosti specifičnih troškova fotonaponske elektrane u zavisnosti od snage. Slika je preuzeta iz literature [3] i prikazuje odnos cena pri kraju 2018. godine u SAD-u. Electrical BOS na slici predstavlja dodatne električne komponente. 


\subsection{Sistemi za praćenje sunca}

Ovi sistemi povećavaju proizvodnju elektrane optimizacijom upadnog ugla direktnog Sunčevog zračenja. Cene kod jednoosnog $\mathrm{C} 1$-axis $(€)$ i dvoosnog C2-axis (€) praćenje u zavisnosti od nominalne snage elektrane PPV $(\mathrm{kW})$ iznose:

$$
\begin{aligned}
& C_{1-a x i s}=86,608 P_{p v}+2951,4 \\
& C_{2-\text { axis }}=280,28 P_{p v}+2641,9
\end{aligned}
$$

\subsection{Cene ostalih komponenata i troškova}

U slučaju nemogućnosti plasiranja električne energije u distributivnu mrežu pri korišćenju sistema koji mogu da proizvedu više električne energije nego što je u datom trenutku potrebno koriste se akumulatori. Ovo su tzv. hibridni sistemi. Najpovoljnije cene akumulatora od $12 \mathrm{~V} 250 \mathrm{Ah}$ se kreće od 175 do $300 €$. Na osnovu ove činjenice u radu je računato sa cenom akumulatora od $78.2 € / \mathrm{kWh}$. Pri modeliranju vodilo se računa da se akumulatori prazne do $30 \%$ a pune do $90 \%$ maksimalnog kapaciteta. Ovakav način rada produžava radni vek akumulatora.

Cene projektovanja i izvođenja radova analizirane su na osnovu trenutnih tržišnih cena u Republici Srbiji. Uglavnom se za izvođenje elektro i mašinskih radova naplaćuje između 20 i 30\% vrednosti opreme koja se ugrađuje. Kod manjih sistema ova cena ide i do $35 \%$. Sa porastom vrednosti opreme koja se ugrađuje opada udeo troškova ugradnje.

U operativne troškove spadaju: administracija nad elektranom, zamena neispravnih delova, nadgledanje i inspekcija sistema, čišćenje modula, održavanje okolne vegetacije i zamena delova sistema. Najčešću zamenu traže delovi sa najmanjim garantnim rokom. Kod hibridnog sistema to su akumulatori čiji je garantni rok svega 3 godine. Kod svih drugih sistema uključujući i hibridne to su inverteri, čiji je garantni rok 5 godina. Za svu drugu elektronsku opremu garantni rok je 5 godina osim za fotonaponske panele za koje proizvođači daju 25 godina garancije. U okviru rada, troškovi rada i održavanja računati su na sledeći način: (1) praćen je trend od 2015. do 2018. godine za troškove u SAD-u [3] i ovi su troškovi ekstrapolirani na 2020. godinu; (2) potom su od njih oduzeti troškovi za inverter i dodati stvarni na sledeći način: pretpostavljeno je da je životni vek invertera 5 godina i da je godišnje smanjenje cene 5\%; (3) kod hibridnih sistema troškovi održavanja su izuzetno visoki zbog potreba za zamenom skupih invertera na svakih 5 godina i baterija na svake 3 godine. Pri ovome je pretpostavljeno da će u budućem periodu cene obe komponente opadati godišnje za $8 \%$. Uticaj inflacije nije uzet u obzir pri računanju ovih troškova u budućnosti.

\subsection{Gubici električne energije}

Pretpostavljeno je da su ukupni gubici u traženju optimalne radne tačke, na kablovima, na inverteru, kao i usled zaprljanosti kolektora $14 \%$ od energije koja se dobija na svim panelima. Ovi gubici su se kretali od 14\% u 2010. godini do $11.4 \%$ u 2018. godini [3]. Imajući u vidu da su pri računanju korišćene prosečne cene invertera kao i to da je lokacija do reke, da je niža od frekventnog puta, da se nalazi u polju gde ima poljoprivrednih radova (odbegle prašine), da iznad nje (po nadmorskoj visini) ima puno ložišta sa čvrstim gorivom i u okviru ovog rada računato je da su ovi gubici 14\%. Gubitke usled upadnog ugla sunčevih zraka, spektralnih efekata, niske dozračene energije i temperature je računao softver [4].

\subsection{Cena električne energije - uštede}

Elektrana ostvaruje dobit smanjenjem troškova pumpanja. Imajući u vidu da analizirano pumpno postrojenje radi sa faktorom snage 0.948 postoje dve mogućnosti za snabdevanje pumpnog postrojenja. One su predstavljene i objašnjene na Slici 4. Koji će od slučajeva nastati zavisi od dogovora sa dobavljačem električne energije. Pri postojećim uslovim, ušteda koju solarno postrojenje pravi ako $1 \mathrm{kWh}$ proizvedene električne energije snabdeva isključivo kao aktivnu snagu je 9.386 din (7.988 s€). Ukoliko se električna energija predaje sa faktorom snage 0.95 tada je cena $1 \mathrm{kWh}$ električne energije 9.218 din (7.845 s€). Razlika u ceni je posledica primenjenog tarifnog sistema.
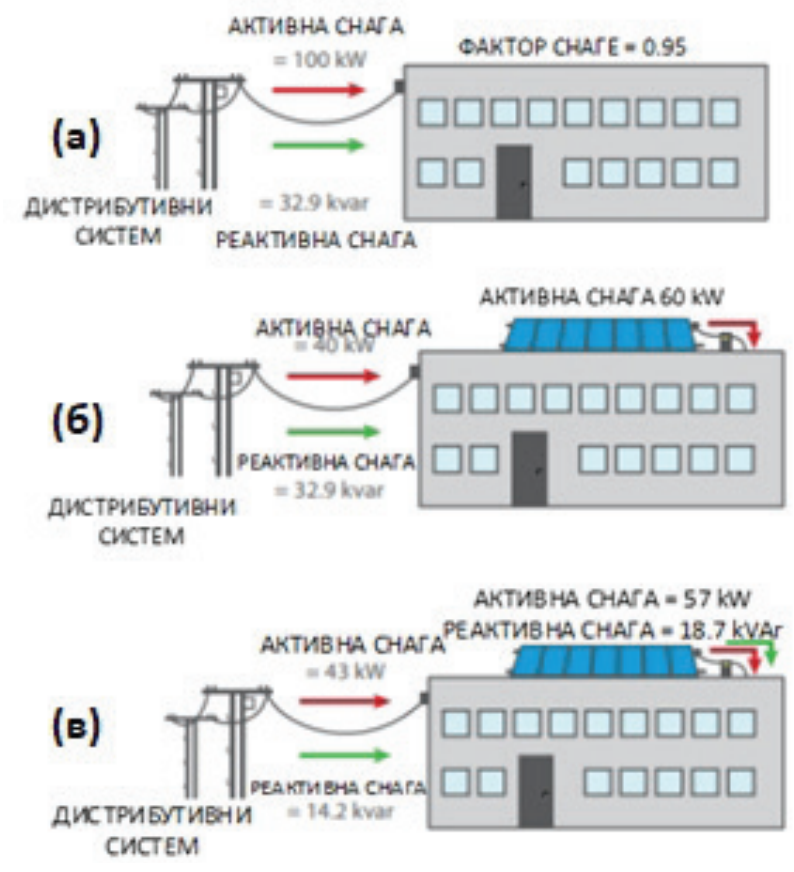

$\overline{\text { Slika 4: Slika je preuzeta iz [11]. a) postojeći način rada pumpnog }}$ postrojenja, b) način rada kad se sva energija koristi kao aktivna - u tom slučaju veća je potrošnja reaktivne energije, v) ako se energija fotonaponskog sistema predaje sa istim faktorm snage sa kojim rade motori, srazmerno se smanjuje potrošnja aktivne i reaktivne energije iz mreže.

\section{Rezultati}

Za analiziranu lokaciju optimalni nagib stacionarno postavljenih kolektora u odnosu na horizontalnu ravan iznosi $35^{\circ}$, dok je optimalni azimut $-3^{\circ}$. Rezultati su provereni i saglasni su sa literaturom [10]. Kod sistema sa jednoosnim praćenjem Sunca, optimalni ugao nagiba kolektora iznosi 370. U poređenju sa stacionarnim sistemom, sistem sa jednoosnim praćenjem proizvodi $27.4 \%$, a sistem sa dvoosnim praćenjem $30.7 \%$ više električne energije na godišnjem nivou pod pretpostavkom da svi sistemi imaju iste fotonaponske panele $\mathrm{i}$ iste gubitke u sistemu. Slika 5. prikazuje godišnju proizvodnju različitih kolektora nazivne snage $1 \mathrm{~kW}$ na datoj lokaciji. 


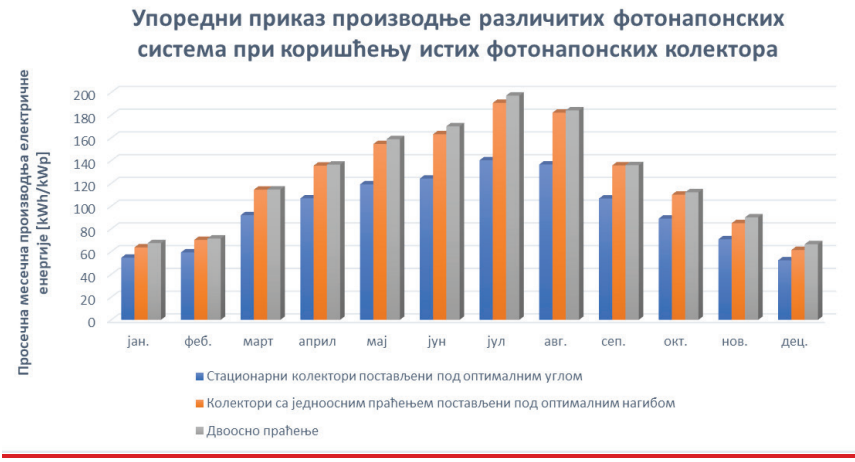

Slika 5: Godišnja proizvodnja električne energije različitih tipova fotonaponskih panela nominalne snage $1 \mathrm{~kW}$ na datoj lokaciji.

Slika 6. prikazuje specifične investicione troškove u zavisnosti od tipa elektrane i vrste primenjenih panela. Specifični troškovi sistema prikačenih na distributivnu mrežu opadaju sa porastom instalirane snage, što je u skladu sa [3]. Nasuprot njima, iznad $\sim 150 \mathrm{~kW}$ raste potreba za relativno skupim baterijama, pa otuda rastu i specifični troškovi investicije. Na sličan način se ponašaju i troškovi rada i održavanja. Oni su viši kod sistema za praćenje Sunca, a naročito su visoki za hibridne sisteme zbog relativno kratkog trajanja baterija (3 godine) $\mathrm{i}$ invertera ( 5 godina).

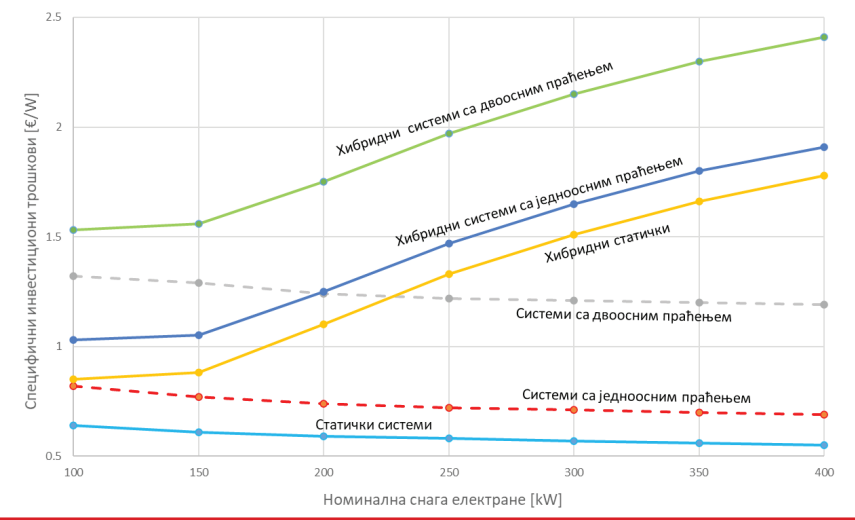

Slika 6: Specifični troškovi investicije u zavisnosti od tipa elektrane, tipa kolektora i nominalne snage

Slika 7. oslikava ekonomsku isplativost investicije u zavisnosti od vrste i veličine sistema i načina na koji se električna energija predaje sistemu. Na slici je prikazana i površina zemljišta koju bi solarna elektrana zauzimala. Ova površina je dobijena tako da redovi solarnih panela ne prave jedan drugom senku ni na dan kratkodnevnice u periodu kad je azimut Sunca između \pm 450 u odnosu na jug, što na analiziranoj lokaciji odgovara vreme u 818 pre podne 21.12. i tada je potrebno rastojanje između solarnih panela $6.655 \mathrm{~m}$. Ako bi se rastojanje između redova panela radilo tako da u podne na dan kratkodnevnice redovi panela jedan drugom ne prave senku, optimalno rastojanje između redova panela iznosilo bi $4.328 \mathrm{~m}$, što bi davalo za $37 \%$ manju ukupnu površinu zemljišta koju zauzima elektrana. Sa slike se može videti:

- da je najisplativije svu električnu energiju iz solarne elektrane predavati sistemu za pumpanje vode kao aktivnu. U odnosu na ovaj slučaj, uštede su za 1.79\% niže ukoliko se električna energije iz solarne elektrane predaje pumpnom sistemu sa faktorom snage 0.95 .

- da su u odnosu na sisteme sa stacionarnim, sistemi sa panelima sa jednoosnim praćenjem Sunca malo isplativiji. Razlika je toliko mala da se sa $100 \%$ sigurnošću ne može tvrditi da su sistemi sa jednoosnim praćenjem povoljniji.

- Pod pretpostavkom da se mali letnji viškovi električne energije mogu prodati po ceni od $3 \mathrm{c} € / \mathrm{kWh}$ optimalna veličina sistema je u opsegu od 200 do $225 \mathrm{kWp}$ nazivne snage. Ova snaga je viša od maksimalne snage koju povlače pumpe iz mreže. Razlog zašto je električna snaga elektrane optimalna u pomenutom opsegu leži u činjenici da ovako dimenzionisan sistem stvara male letnje viškove a odlično koristi prolećne i jesenje mesece kada gotovo sva proizvodnja ide na relativno skupo pumpanje vode.

- iako veći sistemi imaju niže specifične troškove investicije i rada i održavanja, povećanje sistema iznad $240 \mathrm{kWp}$ smanjuje prost period otplate i ostale ekonomske pokazatelje zato što sistemi počinju da proizvode veće količine energije koji se predaju distributivnoj mreži po relativno niskoj ceni.

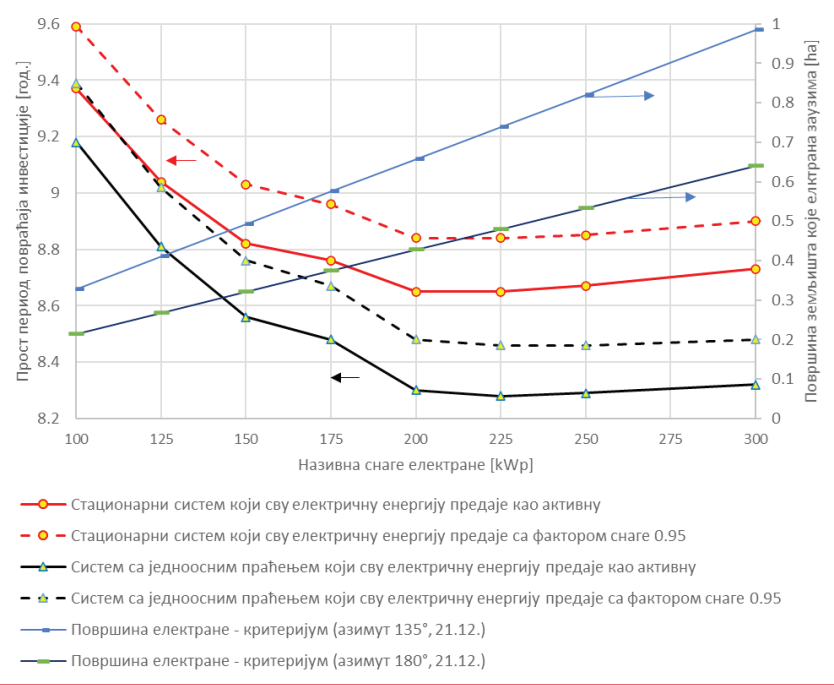

Slika 7: Prost period povraćaja investicije i površina fotonaponske elektrane za sisteme sa stacionarnim i panelima za jednoosno praćenje Sunca pri predaji električne energije pumpnom postrojenju na dva načina: 1. kao aktivna energija i sa faktorom snage 0.95 .

Analizirani sistem je najosetljiviji na vrednost investicionih troškova. Ugrubo se može uzeti da varijacija investicionih troškova za $5 \%$ menja prost period povratka investicije za 0.5 godina. Investicija je manje osetljiva na promenu troškova rada i održavanja, gde se takođe ugrubo može reći da varijacija ovih troškova za $10 \%$ menja prost period povratka investicije za 2 meseca.

\section{$4 \quad$ Zaključak}

Glavni zaključci rada su:

- Pri postojećim cenama električne energije isplativo je 
koristiti solarne fotonaponske sisteme sa stacionarnim i kolektorima za jednoosno praćenje Sunca u postrojenjima na srednjem naponu. Investicioni troškovi su toliko opali da nisu potrebne subvencionisane mere za primenu ovih sistema $u$ ispitivanim uslovima.

- U zavisnosti od vrste sistema koji se snabdeva električnom energijom i njegovog dnevnog profila zahtevane električne postoji optimalna nominalna snaga fotonaponskog sistema. Ona je u slučaju ispitivanog pumpnog postrojenja veća od njegove maksimalne nominalne snage zbog različitog intenziteta sunčevog zračenja u toku dana. Koliko instalirana snaga treba da bude veća od potrebne zavisi, pre svega, od cene po kojoj se prodaju elektrodistributivnoj mreži viškovi proizvedene električne energije.

- $\quad$ Pri postojećem tarifnom sistemu najisplativije je predavati svu proizvedenu električnu energiju snabdevanom sistemu kao aktivnu.

- $\quad$ Sistemi koji predviđaju akumulaciju električne energije, tzv. hibridni sistemi, su neisplativi. Razlog su dodatna ulaganja $\mathrm{u}$ akumulatore i invertere koji zbog kratkih radnih vekova iziskuju visoke troškove rada i održavanja.

- $\quad$ U poređenju sa sistemima sa stacionarnim panelima i panelima sa jednoosnim praćenjem, sistemi sa dvoosnim praćenjem Sunca su ekonomski neisplativi.

- Sistemi sa statičkim i panelima sa jednoosnim praćenjem Sunca su približno iste isplativosti.

- Investicije u ove sisteme su najosetljivije na vrednost investicionih troškova.

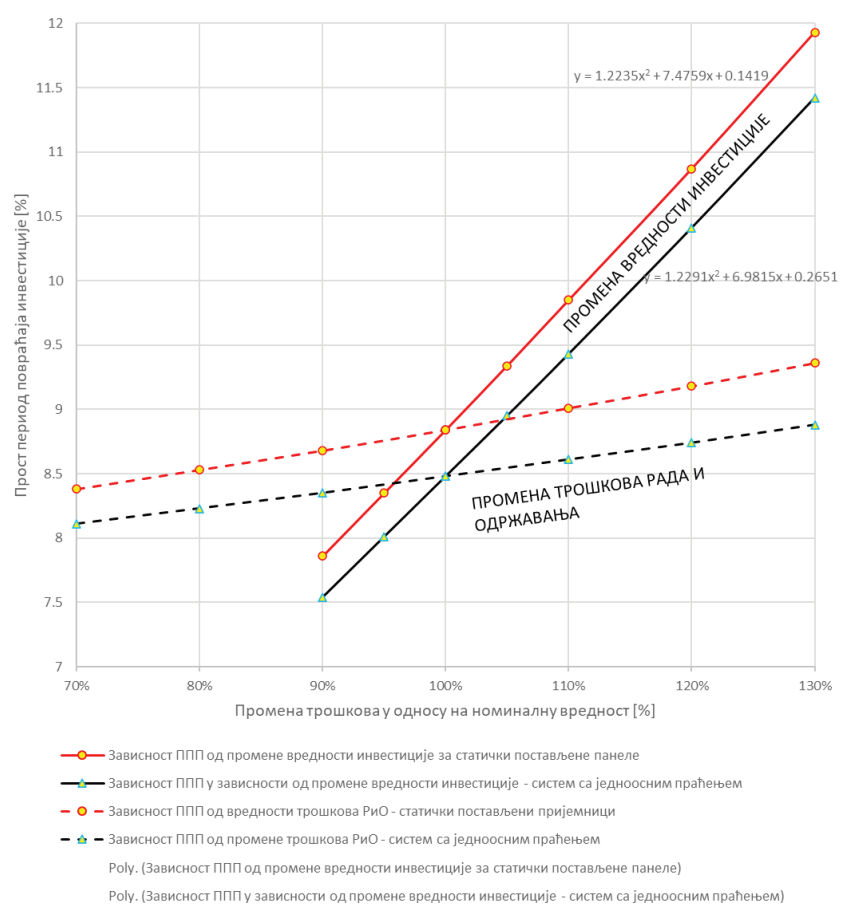

Slika 8: Analiza osetljivosti prostog perioda povratka investicije u zavisnosti od promene vrednosti investicije i promene troškova rada i održavanja. Analiza je sprovedena za sisteme snage $200 \mathrm{kWp}$ bez akumulatora, sa stacionarnim i panelima sa jednoosnim praćenjem Sunca.
Na kraju treba upozoriti da primena fotonaponskih sistema iako spašava klimu narušava životnu sredinu. Obično se njihova primena u našoj zemlji zagovora smanjenjenjem ekvivalentne emisije ugljen dioksida SO2 a prećutkuju se narušavanje flore i faune na mestima elektrane i opasan otpad koji se javlja na kraju životnog veka kolektora i akumulatora. Ove činjenice su veliki nedostatak i analizirane lokacije i navode još jednom na ponavljanje dobro poznatog zaključka: da je fotonaponske elektrane najprikladnije graditi na objektima.

\section{Literatura}

[1] Renewables Global Status Report 2019.

[2] https://www.mre.gov.rs/doc/registar-03082020.html\#Sec_Solar

[3] Ran Fu, David Feldman, and Robert Margolis, U.S. Solar Photovoltaic System Cost Benchmark: Q1 2018, Technical Report NREL/TP-6A20-72399 November 2018.

[4] https://ec.europa.eu/jrc/en/pvgis

[5] http://www.hidmet.gov.rs/ciril/meteorologija/stanica_sr.php?moss $\mathrm{id}=13376 \mathrm{f}$

[6] Baumgartner F., Photovoltaic (PV) balance of system components, in: The Performance of Pho-tovoltaic (PV) Systems, editor Nicola Pearsall, Elsevier 2017.

[7] https://www.mre.gov.rs/doc/efikasnost-izvori/01\%20Uputstvo\%20 za\%20pripremu\%20projekata\%20EE\%20u\%20opstinama.pdf.

[8] Goss B., Cole I.R., Koubli E., Palmer D., Betts T.R., Gottschalg R., Modelling and prediction of $P V$ module energy yield, in: The Performance of Photovoltaic (PV) Systems, editor Nicola Pearsall, Elsevier 2017.

[9] https://www.gses.com.au/wp-content/uploads/2016/03/GSES_ powerfactor-110316.pdf

[10] Mark Z. Jacobson, Vijaysinh Jadhav, World estimates of PV optimal tilt angles and ratios of sunlight incident upon tilted and tracked PV panels relative to horizontal panels, Solar Energy (2018) 55-66

[11] https://www.gses.com.au/wp-content/uploads/2016/03/GSES_ powerfactor-110316.pdf

\section{Autori \\ Rade Karamarković \\ Univerzitet u Kragujevcu, Fakultet za mašinstvo i građevinarsto, Kraljevo, Srbija

\author{
Dragiša Šimunović \\ Univerzitet u Kragujevcu, Fakultet za mašinstvo i \\ građevinarsto, Kraljevo, Srbija
}

\author{
Miloš Nikolić \\ Univerzitet u Kragujevcu, Fakultet za mašinstvo i \\ građevinarsto, Kraljevo, Srbija
}

\author{
Miljan Marašević \\ Univerzitet u Kragujevcu, Fakultet za mašinstvo i \\ građevinarsto, Kraljevo, Srbija
}

\section{Đorđe Novčić}

Univerzitet u Kragujevcu, Fakultet za mašinstvo i građevinarsto, Kraljevo, Srbija 